\title{
Treatment Outcomes in Patients Receiving Regorafenib for Metastatic Colon Cancer
}

\author{
L Fok, KM Cheung, YL Kwok, KH Wong \\ Department of Clinical Oncology, Queen Elizabeth Hospital, Jordan, Hong Kong
}

\begin{abstract}
Objectives: To review the treatment outcomes of patients with chemorefractory metastatic colorectal cancer receiving the multikinase inhibitor regorafenib.

Methods: This was a retrospective cohort study including patients who received regorafenib after failure of standard irinotecan- and oxaliplatin-based chemotherapy with or without biologics from 2016 to 2018 in a single centre in Hong Kong.

Results: Fourteen patients met the inclusion criteria. All had good general condition (i.e., Eastern Cooperative Oncology Group score 1). Seven patients had received bevacizumab previously. Median progression-free survival (PFS) was 12.4 weeks and median overall survival (OS) was 26.5 weeks. Eight patients had grade $\geq 3$ adverse events and $10(71.4 \%)$ required temporary treatment suspension. The commonest grade $\geq 3$ adverse events were palmarplantar erythrodysaesthesia and fatigue (both 28.6\%). Patients with a carcinoembryonic antigen drop of $\geq 50 \%$ from baseline enjoyed longer PFS, though not to a significant extent. OS was longer for left-sided primary tumours $(202$ vs. 57 days, $p=0.001)$. Two patients with good performance after progression received trifluridine-tipiracil. Their median $O S$ was 400 days.

Conclusion: Our experience with regorafenib monotherapy for patients with chemorefractory metastatic colorectal cancer was comparable to the landmark trials. The grade $\geq 3$ adverse events were frequent, and dose reduction or treatment delay was required. Potentially favourable prognostic factors included a left-sided primary tumour and a carcinoembryonic antigen drop from baseline. Those who received further treatment after regorafenib enjoyed reasonably long survival. Treatment after regorafenib with newer strategies should be considered in those who remain functional.
\end{abstract}

Key Words: Colorectal neoplasms; Protein kinase inhibitors

Correspondence: Dr L Fok, Department of Clinical Oncology, Queen Elizabeth Hospital, Jordan, Hong Kong Email:leslie.fok@link.cubk.edu.hk

Submitted: 7 Jun 2019; Accepted: 3 Sep 2019.

Contributors: LF and KMC designed the study and acquired the data. All authors contributed to the analysis of data, drafted the manuscript, and had critical revision of the manuscript for important intellectual content. All authors had full access to the data, contributed to the study, approved the final version for publication, and take responsibility for its accuracy and integrity.

Conflicts of Interest: The authors have no conflicts of interest to disclose.

Funding/Support: This research received no specific grant from any funding agency in the public, commercial, or not-for-profit sectors.

Ethics Approval: This study was approved by the Research Ethics Committee (Kowloon Central/Kowloon East) of the Hospital Authority, Hong Kong (Ref KC/KE-19-0046-ER/4). The requirement for patient consent was waived. All patients were treated in compliance with the Declaration of Helsinki. 


\title{
中文摘要
}

\section{瑞戈非尼對大腸癌轉移患者的治療結果}

\author{
霍善智、張嘉文、郭婉琳、黃錦洪 \\ 目的 : 探討多激酶抑制劑瑞戈非尼對化療難治性大腸癌轉移患者的治療結果。 \\ 方法 : 這項回顧性隊列研究納入2016年至2018年於香港單一中心進行標準伊立替康和奧沙利鉑化 \\ 療無效後接受瑞戈非尼治療合用或未合用生物製劑的患者。 \\ 結果：14名患者符合納入標準。所有患者的身體狀況較好（ECOG 1分）, 當中7名患者曾接受貝 \\ 伐單抗治療。無惡化存活期中位數為 12.4 週, 總體存活期中位數為 26.5 週。8名患者出現 $\geq 3$ 級不良 \\ 事件, 10 名患者 $(71.4 \%)$ 須暫停治療。最常見 $\geq 3$ 級不良事件包括掌足紅腫綜合徵和疲勞（均為 \\ $28.6 \%$ ）。癌胚抗原從基線下降 $\geq 50 \%$ 的患者有更長無惡化存活期, 但只有邊緣顯著性。左側原發 \\ 腫瘤患者的總體存活期較長 $(202$ 天比 57 天, $\mathrm{p}=0.001)$ 。兩名患者在瑞戈非尼治療失敗後因體能 \\ 狀態較佳, 遂以三氟胸苷一替吡嘧啶作進一步治療。他們的總體存活期中位數為 400 天。 \\ 結論 : 本研究的瑞戈非尼單藥治療化療難治性大腸癌轉移患者的經驗與具有里程碑意義的試驗相 \\ 若。 $\geq 3$ 級不良事件很常見, 須減少劑量或延遲治療。潛在的有利預後因素包括左側原發腫瘤和癌 \\ 胚抗原從基線下降。瑞戈非尼後接受進一步治療患者有較長存活期。使用瑞戈非尼後仍保持功能 \\ 的患者, 可考慮以新策略作進一步治療。
}

\section{INTRODUCTION}

Colorectal cancer is the commonest malignancy in Hong Kong, with an age-standardised incidence rate of 35.7 per 100000 population in $2016 .{ }^{1} \mathrm{Up}$ to $23 \%$ of patients have metastatic disease on presentation, and the 5-year overall survival (OS) is $14 \%{ }^{2}$

Traditionally, chemotherapy and biologics using fluoropyrimidine, irinotecan and oxaliplatin, with or without anti-vascular endothelial growth factor (VEGF) agents and anti-epithelial growth factor receptor (EGFR) agents for $R A S$ wild-type tumours, were the main treatment strategies for inoperable or metastatic colorectal cancer (mCRC). Despite the range of available combination therapies, OS remained in the range of 20 to 30 months. ${ }^{3}$ Options beyond these standard treatments were limited, with regorafenib and trifluridine-tipiracil being the only two Food and Drug Administration (FDA)-approved treatments for this group of patients. ${ }^{4}$

Regorafenib is an oral multikinase inhibitor, which is structurally similar to sorafenib. It blocks multiple kinases involved in tumour angiogenesis (VEGFR 1-3, Tie2), oncogenesis (KIT, RET, RAF1 and BRAF), and tumour microenvironment (PDGFR and FGFR). In an international multicentre phase III trial (CORRECT), statistically significant, yet modest improvement in OS was demonstrated compared with placebo in patients with colorectal cancer who had failed multiple lines of chemotherapy (6.4 months vs. 5.0 months, hazard ratio $=0.77,95 \%$ confidence interval $[\mathrm{CI}]=0.64-0.94$, $\mathrm{p}=0.0052) .{ }^{5}$ The results were similar in a subsequent study targeting Asian populations. ${ }^{6}$ However, grade 3 or 4 adverse events (AEs) were high in both trials and in real-world settings, ${ }^{7}$ affecting $>50 \%$ of patients. The modest magnitude of survival prolongation and its significant toxicity suggests the importance of careful patient selection and the urgency of identification of additional treatment strategies. We aimed to review our experience in using regorafenib monotherapy as a lastline treatment, and to investigate predictive markers of treatment response.

\section{METHODS Patients}

This study was approved by the ethics committee of Kowloon Central Cluster/Kowloon Eastern Cluster of the Hospital Authority and conducted in compliance with the Declaration of Helsinki. Records of patients with stage IV colorectal adenocarcinoma who received regorafenib from January 2016 to December 2018 in the Department of Clinical Oncology of Queen Elizabeth Hospital were retrieved and retrospectively analysed. Patients were offered regorafenib after exhausting all available treatments at that time, which included chemotherapy fluoropyrimidine, irinotecan and oxaliplatin; and 
biologics with bevacizumab and cetuximab if clinically suitable and affordable.

\section{Treatment}

Regorafenib was provided either on a compassionate basis from the pharmaceutical company or as a selffinanced item during the study period. Patients received regorafenib $160 \mathrm{mg}$ daily for the first 3 weeks of each 4-week cycle until disease progression, death, intolerable AEs, or patients' refusal to continue / inability to afford treatment. Lower starting doses and dose reduction or escalation during treatment were allowed per clinical judgement of the prescribing physician.

\section{Assessment}

Patients were followed up fortnightly with routine monitoring of complete blood counts, liver and renal function tests, and carcinoembryonic antigen (CEA) levels. Interval computed tomography scanning was arranged every 10 to 12 weeks. The RECIST (Response Evaluation Criteria in Solid Tumour) version 1.1 was referred to in order to determine treatment response. AEs were defined and graded according to the CTCAE (Common Terminology Criteria for Adverse Events) version 4.0 by National Cancer Institute. A CEA response was defined as a decrease of CEA from baseline after the start of regorafenib.

\section{Statistical Analyses}

Statistical analyses were performed with SPSS (Windows version 26.0; IBM Corp, Armonk [NY], United States). Descriptive statistics on central tendency (e.g., mean, median) and data dispersion (e.g., range, standard deviation, 95\% CI) were used. The KaplanMeier method and log-rank test were used to depict and analyse survival outcomes. A p value of $<0.05$ was considered significant.

\section{RESULTS \\ Patient Characteristics}

From January 2016 to December 2018, a total of 14 mCRC patients received regorafenib. Patient baseline characteristics are summarised in Table 1 . The median age was 61.3 years. All patients had an Eastern Cooperative Oncology Group (ECOG) performance score of 1 . In all, $57.1 \%$ of them had primary colon cancer while the rest had primary rectal cancer. In total, $85.7 \%$ had liver metastases when regorafenib treatment was initiated, and approximately $60 \%$ of them had three or more metastatic sites. Approximately $70 \%$ of the patients had K- or N-Ras mutant tumours. Half of
Table 1. Patient demographics. *

\begin{tabular}{|c|c|}
\hline Characteristic & Value \\
\hline Age, median, years & $61.3(42.1-73)$ \\
\hline \multicolumn{2}{|l|}{ Sex } \\
\hline Male & $10(71.4 \%)$ \\
\hline Female & $4(28.6 \%)$ \\
\hline \multicolumn{2}{|l|}{ ECOG performance score } \\
\hline 1 & $14(100 \%)$ \\
\hline \multicolumn{2}{|l|}{ Tumour location } \\
\hline Colon & $8(57.1 \%)$ \\
\hline Rectum & $6(42.9 \%)$ \\
\hline \multicolumn{2}{|l|}{ Sidedness of tumour } \\
\hline Left-sided & $12(85.7 \%)$ \\
\hline Right-sided & $2(14.3 \%)$ \\
\hline \multicolumn{2}{|l|}{ Presence of liver metastases } \\
\hline Yes & $12(85.7 \%)$ \\
\hline No & $2(14.3 \%)$ \\
\hline \multicolumn{2}{|l|}{$\mathrm{K}-/ \mathrm{N}-$ Ras status } \\
\hline Wild type & $4(28.6 \%)$ \\
\hline Mutant & $10(71.4 \%)$ \\
\hline \multicolumn{2}{|l|}{ Previous anti-VEGF exposure } \\
\hline Yes & $7(50 \%)$ \\
\hline No & $7(50 \%)$ \\
\hline \multicolumn{2}{|l|}{$\begin{array}{l}\text { Previous anti-EGFR exposure (Ras wild- } \\
\text { type only) }\end{array}$} \\
\hline Yes & $3(75 \%)$ \\
\hline No & $1(25 \%)$ \\
\hline Lines of previous treatment, median (range) & $2(2-5)$ \\
\hline$\leq 2$ & $9(64.3 \%)$ \\
\hline$>2$ & $5(35.7 \%)$ \\
\hline CEA response to treatment & $11(78.6 \%)$ \\
\hline Median response & $-33.5 \%(-14 \%$ to $-73 \%)$ \\
\hline$\leq 50 \%$ & $7(63.6 \%)$ \\
\hline$>50 \%$ & $4(36.4 \%)$ \\
\hline Time to CEA nadir, median (range), days & $21(14-71)$ \\
\hline
\end{tabular}

the patients had undergone anti-VEGF therapy prior to starting regorafenib. In the Ras wild-type subgroup, three $(75 \%)$ of the patients had received an anti-EGFR agent. One patient $(25 \%)$ chose not to receive anti-EGFR therapy due to affordability. The median number of lines of systemic therapy before regorafenib was two. Only two patients continued onto a next line of treatment after failure of regorafenib. The rest either had died by the time of progression $(n=2)$, were unfit for further oncological treatment due to disease progression $(n=4)$, or were unable to afford any more treatment $(n=6)$.

\section{Response}

The median number of cycles of regorafenib received was 2.67 . The median dose intensity was $75 \%$ of the full dose. Three patients achieved radiographically stable disease, while the 11 others developed progressive disease during regorafenib treatment. The overall 
disease control rate was thus $21.4 \%$. At the same time, patients' CEA response was analysed. All patients had baseline CEA elevation (median CEA $=61$; range, 8.31594). Eleven patients (78.6\%) had a drop in CEA after starting regorafenib. The median time to CEA nadir was 3 weeks and the median drop in CEA was $33.5 \%$ (range, $14 \%-73 \%$ ). Using $50 \%$ as a cut-off, which was a value also used in larger studies, ${ }^{13}$ seven $(63.6 \%)$ of the CEA responders had a drop in CEA $\leq 50 \%$, while four $(36.4 \%)$ of them had a drop of $>50 \%$. No statistically significant correlation was found between the degree of CEA drop and the respective radiological response (Fisher's exact test, $\mathrm{p}=1.00)$.

\section{Tolerance}

\section{Average Time to Temporary Treatment Suspension}

Ten patients $(71.4 \%)$ required temporary treatment suspension during their course of regorafenib due to toxicities. The mean total time of suspension was 1.7 weeks, and the mean time of suspension per treatment cycle was 4.9 days.

\section{Adverse Events}

Table 2 shows a summary of all the treatment-related AEs. Nine patients (64.3\%) experienced toxicity of any kind and grade. Most AEs were severe, with eight patients $(57.1 \%)$ having grade $\geq 3$ AEs. The most common AEs were palmar-plantar erythrodysaesthesia and fatigue (both $28.6 \%$ ). Ten patients $(71.4 \%)$ required suspension at some point in their treatment.

\section{Survival}

\section{Progression-free Survival}

After a median follow-up of 194 days, disease progression was noted in 13 patients. The median progression-free survival (PFS) was 87 days (95\% CI $=81.3-92.6$ days). In univariate analysis, PFS was not significantly worse for patients with a lower regorafenib starting dose or who required dose reduction $(\mathrm{n}=4)$, nor was it associated with mean delay per cycle or the mean dose throughout treatment (Table 3). The association between a $>50 \%$ decrease in CEA and better PFS was not significant ( 89 vs. 74 days, $p=0.05$ ) [Figure 1].

\section{Overall Survival}

The median OS was 186 days ( $95 \% \mathrm{CI}=131-241$ days). Patients with left-sided tumours had longer OS when compared with those with right-sided tumours (202 vs. 57 days, $p=0.001$ ) [Figure 2]. No other factors were significantly associated with OS (Table 3 ).
Table 2. Treatment-related adverse events $(n=14)$.

\begin{tabular}{lll}
\hline Adverse events & Any grade & Grade $\geq 3$ \\
\hline Any adverse event & $9(64.3 \%)$ & $8(57.1 \%)$ \\
Fatigue & $4(28.6 \%)$ & $4(28.6 \%)$ \\
Palmar-plantar erythrodysaesthesia & $6(42.9 \%)$ & $4(28.6 \%)$ \\
Diarrhoea & 0 & 0 \\
Hypertension & $2(14.3 \%)$ & 0 \\
Mucositis & $1(7.1 \%)$ & 0 \\
Leucopenia & 0 & 0 \\
Thrombocytopenia & $1(7.1 \%)$ & 0 \\
Proteinuria & $2(14.3 \%)$ & 0 \\
Hyperbilirubinaemia & $1(7.1 \%)$ & $1(7.1 \%)$ \\
Thromboembolic event & $1(7.1 \%)$ & 0 \\
Gastrointestinal bleeding & $2(14.3 \%)$ & $1(7.1 \%)$ \\
Hypertransaminasaemia & $2(14.3 \%)$ & 0 \\
\hline
\end{tabular}

* Data are shown as No (\%).

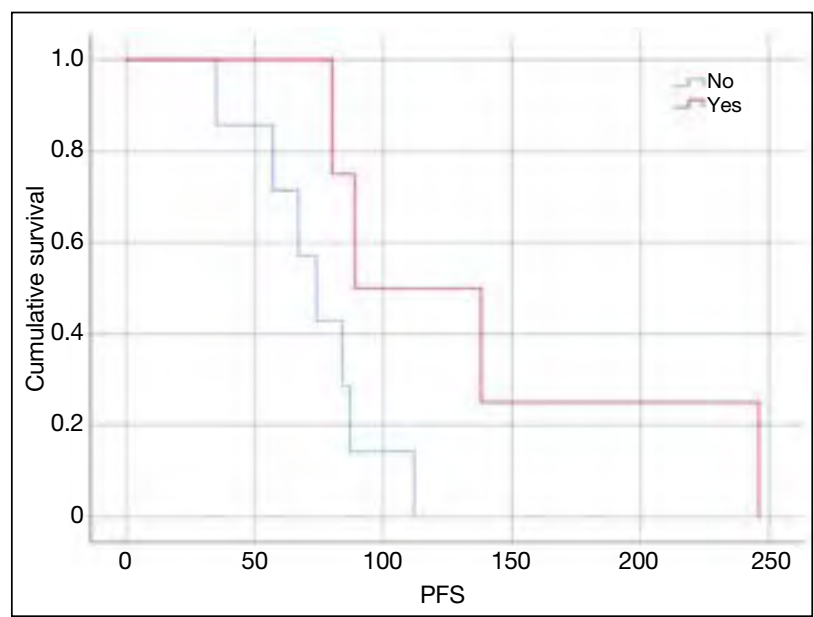

Figure 1. Kaplan-Meier analysis of progression-free survival (PFS) in patients with carcinoembryonic antigen drop $>50 \%$ from baseline (red line) or $\leq 50 \%$ from baseline (blue line).

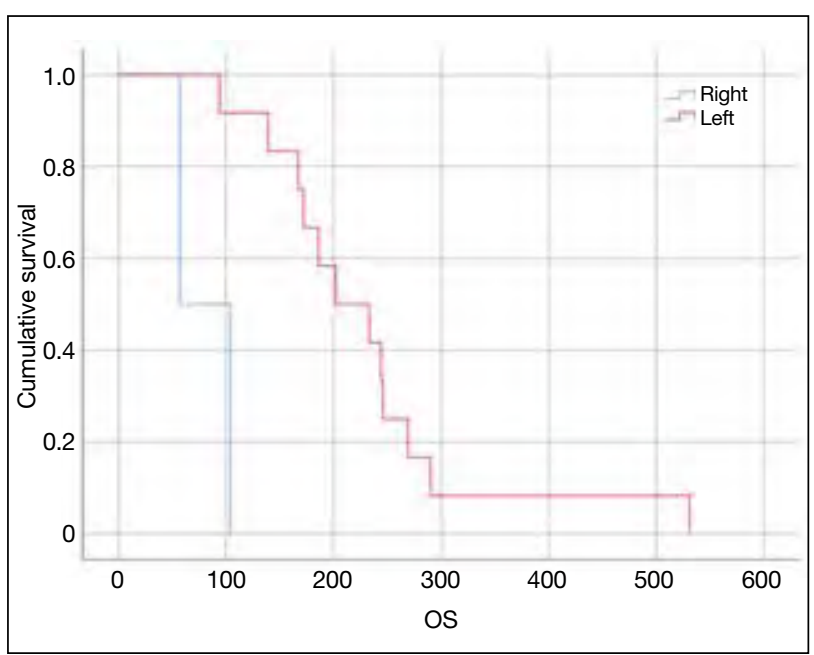

Figure 2. Kaplan-Meier analysis in patients with left- (red line) or right-sided (blue line) primary location. 
Table 3. Patient OS and PFS comparison.

\begin{tabular}{|c|c|c|c|c|}
\hline Parameters & PFS (days) & $\mathrm{p}$ Value & OS (days) & $\mathrm{p}$ Value \\
\hline Median & 87.0 & & 186 & \\
\hline \multicolumn{5}{|c|}{ Lower starting dose } \\
\hline Yes & 87.0 & 0.85 & 139.0 & 0.32 \\
\hline No & 138.0 & & 233.0 & \\
\hline \multicolumn{5}{|c|}{ Dose escalation during treatment } \\
\hline Yes & 80.0 & 0.53 & 186.0 & 0.16 \\
\hline No & 89.0 & & 172.0 & \\
\hline \multicolumn{5}{|c|}{ Dose reduction during treatment } \\
\hline Yes & 89.0 & 0.84 & 172.0 & 0.69 \\
\hline No & 84.0 & & 186.0 & \\
\hline \multicolumn{5}{|l|}{ Mean dose } \\
\hline$<120 \mathrm{mg}$ & 74.0 & 0.82 & 172.0 & 0.85 \\
\hline$\geq 120 \mathrm{mg}$ & 87.0 & & 186.0 & \\
\hline \multicolumn{5}{|c|}{ Sidedness of tumour } \\
\hline Left & 84.0 & 0.62 & 202.0 & 0.001 \\
\hline Right & 35.0 & & 57.0 & \\
\hline \multicolumn{5}{|l|}{ RAS status } \\
\hline Wild type & 89.0 & 0.96 & 104.0 & 0.17 \\
\hline Mutant & 80.0 & & 202.0 & \\
\hline \multicolumn{5}{|c|}{ Previous lines of treatment } \\
\hline$\leq 2$ & 87.0 & 0.39 & 202.0 & 0.92 \\
\hline$>2$ & 74.0 & & 172.0 & \\
\hline \multicolumn{5}{|c|}{ Previous anti-VEGF } \\
\hline Yes & 80.0 & 0.22 & 167.0 & 0.17 \\
\hline No & 89.0 & & 233.0 & \\
\hline \multicolumn{5}{|c|}{ Liver metastases } \\
\hline Presence & 84.0 & 0.28 & 172.0 & 0.43 \\
\hline Absence & 62.0 & & 246.0 & \\
\hline \multicolumn{5}{|c|}{ No. of metastatic sites } \\
\hline$<3$ & 80.0 & 0.53 & 172.0 & 0.48 \\
\hline$\geq 3$ & 84.0 & & 233.0 & \\
\hline \multicolumn{5}{|c|}{ Total time of treatment delay } \\
\hline$\leq 1$ week & 74.0 & 0.11 & 167.0 & 0.71 \\
\hline$>1$ week & 112.0 & & 202.0 & \\
\hline \multicolumn{5}{|l|}{ CEA drop } \\
\hline$\leq 50 \%$ & 74.0 & 0.05 & 172.0 & 0.93 \\
\hline$>50 \%$ & 89.0 & & 202.0 & \\
\hline
\end{tabular}

Abbreviations: CEA = carcinoembryonic antigen; OS = overall survival; PFS = progression-free survival; VEGF = vascular endothelial growth factor.

\section{Subsequent Treatment}

Only two (14\%) of the patients had satisfactory World Health Organization performance status (i.e., ECOG score 1) and were able to afford and undergo further treatment after disease progression. All of them received trifluridine-tipiracil (Lonsurf; Taiho Oncology, Japan) after regorafenib. Their survivals after regorafenib were 207 and 464 days, respectively.

\section{DISCUSSION}

Regorafenib is one of the few treatment options available for mCRC that has failed oxaliplatin- and irinotecanbased chemotherapy. In two large international randomised controlled phase III studies, CORRECT ${ }^{5}$ and CONCUR, ${ }^{6}$ the median PFS was approximately 60.9 to 91.3 days, and the OS was approximately 197.8 to
273.9 days. In the current study, the median PFS was 87 days (95\% $\mathrm{CI}=81.3-92.6$ days) and the median OS was 186 days (95\% CI $=131-241$ days), which are comparable to these two phase III studies.

AEs remain a concern in treatment with regorafenib. In both the CORRECT and CONCUR trials, 54\% of the patients experienced grade $\geq 3 \mathrm{AEs}, 5,6$ which are similar to our study (57.1\%). The most common AE in our study was palmar-plantar erythrodysaesthesia, with $>40 \%$ of patients affected. Approximately two-thirds of these patients had grade $\geq 3$ palmar-plantar erythrodysaesthesia, which commonly led to treatment suspension. Although only $28.6 \%$ of the patients experienced fatigue, all of them reported grade 3 fatigue (fatigue limiting self-care) during the course of treatment. The occurrence of fatigue 
in trials varies considerably. In the CONCUR trial, only $17 \%$ of patients reported fatigue of any grade and only $2.9 \%$ had fatigue of grade $\geq 3 .{ }^{6}$ In contrast, $48 \%$ of patients experienced fatigue in the CORRECT trial, with $9.6 \%$ of them having fatigue grade $\geq 3 .{ }^{5}$ In a systematic review, the incidence of fatigue ranges from $2 \%$ to $73 \%$ in different studies. ${ }^{8}$

As regorafenib is associated with significant rates of AEs when used at full dose, the optimisation of dosing and schedule is a widely discussed topic. From our data, intercycle delay was common, with $>70 \%$ of patients experiencing a mean of 4.9 days of delay per treatment cycle due to AEs, but without a statistically significant impact on survival outcome. The PFS and OS for lower starting doses were shorter than those of the usual starting dose, but not significantly shorter. Outcomes also appeared to be independent of dosing strategies (interval dose reduction or interval dose escalation). In ReDOS, a randomised phase II study, patients were randomised to receive a starting dose of $80 \mathrm{mg}$ with subsequent dose escalation, or a standard starting dose of $160 \mathrm{mg}$. The survival outcomes were not significantly different. ${ }^{9}$ While the small sample size limits robust statistical inference, our data concur with the latest evidence. As the slow dose escalation approach appears to result in better tolerability and safety, we expect it to gain popularity in the near future. Other strategies on management of AEs have also been explored, though efficacy is limited. For example, for treatment-related fatigue, one phase II study investigated the effect of dexamethasone on these patients but failed to show any improvement. ${ }^{10}$

Currently there is no established marker to predict the treatment response towards regorafenib. In our study, patients with left-sided tumours enjoyed longer OS, which concurs with the findings of many other studies that left-sided tumours carry a better prognosis regardless of treatment, stage, race of patients, or length of study. ${ }^{11}$ Some retrospective studies also suggest that in addition to its prognostic implications, primary tumour location may be a predictive factor for treatment response in the first-line setting. ${ }^{12}$ Whether such predictive value also applies to regorafenib warrants further study.

Although not significant, our results showed a marginal association between drop in CEA and PFS. The median time to CEA nadir was found to be 3 weeks. There is no strong evidence on how the degree of CEA decrease correlates with clinical response, and most studies have used arbitrary cut-offs for CEA analysis. We used 50\% as an arbitrary cut-off, which was a value also used in larger studies. ${ }^{13}$ As most of the CEA responders only achieved stable disease in radiological assessment, it may be suggested that the benefit observed in patients with a drop in CEA of $>50 \%$ is independent of radiological response. The absolute reading of CEA is known to reflect tumour burden and carries a prognostic value in patients with $\mathrm{mCRC}$, and was reported to have a role in predicting treatment failure in the absence of readily measurable disease response. ${ }^{14}$ Further verification is needed in a prospective manner to evaluate its prognostic value.

Treatment beyond regorafenib is limited and no clinical guidelines suggest an agreed-upon next line of treatment, although trifluridine-tipiracil (Lonsurf), the other drug licensed for use in refractory $\mathrm{mCRC}$, is a frequent treatment of choice. In our study, only two patients underwent further treatment with trifluridine-tipiracil, and the survival time was considerably long (median, 400 days). Trifluridine-tipiracil consists of a nucleoside analogue (trifluridine) and a thymidine phosphorylase inhibitor (tipiracil) which causes DNA strand breaks. ${ }^{15}$ The different mode of action may explain the longer disease control in patients who have failed regorafenib. Treatment after regorafenib rather than best supportive care is therefore a reasonable option provided that patients are still fit for systemic treatment.

A number of limitations of this study should be acknowledged. First, the eligible population was small $(n=14)$ as only a proportion of patients remained fit for further treatment after failing multiple lines of chemotherapy. The considerable cost of regorafenib (a self-financed item) also limited the number of eligible patients. As a result, it can only be deduced that there was a tendency suggesting that good response of CEA and a left-sided primary tumour were favourable prognostic factors in patients using regorafenib, and this should be verified in a larger prospective study. Second, the cut-off used for CEA analysis was arbitrary, without verification by prospective data. Finally, the report of toxicity outcomes is also compromised by its retrospective nature and the subjectivity of toxicities like fatigue.

With the advancements in molecular studies, more options will be available for patients with $\mathrm{mCRC}$ who have run out of treatment choices. The BRAF mutation is found in approximately $5 \%$ to $10 \%$ of patients with mCRC. ${ }^{16}$ It is known to carry a poor prognosis, ${ }^{17}$ and is a predictive factor for poor response to anti-EGFR 
therapy in Ras wild-type patients, ${ }^{18}$ so much so that established international guidelines do not recommend anti-EGFR therapy in patients who harbour the $B R A F$ mutation. ${ }^{19}$ Among these patients, monotherapy with the $B R A F$ inhibitor vemurafenib failed to show a meaningful activity in $B R A F^{\mathrm{V} 600 \mathrm{E}}$-mutated mCRC. ${ }^{20}$ In a phase I/II open-label study, more than half of the study population achieved a stable disease after a combination of the $B R A F$ inhibitor dabrafenib, and the $M E K$ inhibitor trametinib. The overall response rate was $12 \%$ and the median PFS was 3.5 months (95\% CI $=3.4-4.0$ months). ${ }^{21}$ Immune checkpoint inhibitors have been shown to benefit patients with deficient mismatch repair (dMMR), which is characterised by a high number of DNA replication errors and high levels of DNA microsatellite instability. The dMMR tumours are present in approximately 5\% of patients with $\mathrm{mCRC}^{22}$ and are known to carry a poor prognosis, which is driven by its association with the $B R A F$ mutation. ${ }^{17}$ In a phase II study looking at the use of pembrolizumab in patients with mCRC, an objective response rate (ORR) of 50\% was achieved in patients with dMMR, while none was achieved in patients with proficient mismatch repair. ${ }^{23}$ OS and PFS have not been reached for patients with dMMR, whereas the OS was 7.6 months and the PFS was 2.3 months for patients with proficient mismatch repair. As a result, pembrolizumab has been granted an indication by the FDA for its use in colorectal cancer that has progressed following treatment with a fluoropyrimidine, oxaliplatin, and irinotecan without satisfactory alternative treatment options. Nivolumab, a monoclonal antibody against programmed cell death protein 1 , is another option for patients with dMMR. In the CheckMate 142 trial that looked at nivolumab \pm ipilimumab, a monoclonal antibody against cytotoxic T-lymphocyte antigen 4, in heavily pretreated patients with $\mathrm{mCRC}$, the ORR with nivolumab monotherapy was $31.1 \% .^{22}$ It was even higher in the nivolumab plus ipilimumab group with an ORR of $55 \%$. Grade 3 to 4 toxicities were observed in $20 \%$ in the monotherapy group, and $29 \%$ in the doublet group. ${ }^{24}$ Based on these results, FDA indications have been granted for the use of nivolumab in patients with dMMR who have failed a fluoropyrimidine, oxaliplatin, and irinotecan; and for the use of nivolumab plus ipilimumab for patients with previously treated dMMR mCRC.

In patients with unclear dMMR status, addition of nivolumab to regorafenib has been investigated in REGONIVO, a phase IB study. This strategy yielded an ORR of $38 \%$ in the unselected population, and an even higher response in patients with microsatellite instability-high CRC (44\%). ${ }^{25}$ When used with nivolumab, reduction of the starting dose of regorafenib to $80 \mathrm{mg}$ rendered this regimen more tolerable.

\section{CONCLUSION}

Treatments for mCRC after oxaliplatin- and irinotecanbased chemotherapy remain limited. Our institutional experience with regorafenib was generally consistent with the available literature. Our study also found that there is a tendency towards a longer duration of stable disease in patients with an initial drop of CEA after starting regorafenib and a left-sided primary tumour. Treatment beyond regorafenib in those who remain medically fit and are able to afford more treatment resulted in a favourable OS. With the promise of novel agents shown to be highly effective in selected populations, and their overall favourable toxicity profile, further prospective studies are warranted.

\section{REFERENCES}

1. Hong Kong Cancer Registry, Hospital Authority, Hong Kong SAR Government. 2016. Available from: https://www3.ha.org. hk/cancereg Accessed 24 Apr 2019.

2. National Cancer Institute, Department of Health and Human Service, US Government. Surveillance, Epidemiology, and End Results (SEER) Program Research Data (1975-2016), National Cancer Institute, DCCPS, Surveillance Research Program. Available from: https://www.seer.cancer.gov. Accessed 1 Jun 2019.

3. Jawed I, Wilkerson J, Prasad V, Duffy AG, Fojo T. Colorectal cancer survival gains and novel treatment regimens: a systematic review and analysis. JAMA Oncol. 2015;1:787-95. Crossref

4. Yoshino T, Arnold D, Taniguchi H, Pentheroudakis G, Yamazaki $\mathrm{K}, \mathrm{Xu} \mathrm{RH}$, et al. Pan-Asian adapted ESMO consensus guidelines for the management of patients with metastatic colorectal cancer: a JSMO-ESMO initiative endorsed by CSCO, KACO, MOS, SSO and TOS. Ann Oncol. 2018;29:44-70. Crossref

5. Grothey A, Van Cutsem E, Sobrero A, Siena S, Falcone A, Ychou M, et al. Regorafenib monotherapy for previously treated metastatic colorectal cancer (CORRECT): an international, multicentre, randomised, placebo-controlled, phase 3 trial. Lancet. 2013;381:303-12. Crossref

6. Li J, Qin S, Xu R, Yau TC, Ma B, Pan H, et al. Regorafenib plus best supportive care versus placebo plus best supportive care in Asian patients with previously treated metastatic colorectal cancer (CONCUR): a randomised, double-blind, placebo-controlled, phase 3 trial. Lancet Oncol. 2015;16:619-29. Crossref

7. Lam KO, Lee KC, Chiu J, Lee VH, Leung R, Choy TS, et al. The real-world use of regorafenib for metastatic colorectal cancer: multicentre analysis of treatment pattern and outcomes in Hong Kong. Postgrad Med J. 2017;93:395-400. Crossref

8. Røed Skårderud M, Polk A, Kjeldgaard Vistisen K, Larsen FO, Nielsen DL. Efficacy and safety of regorafenib in the treatment of metastatic colorectal cancer: A systematic review. Cancer Treat Rev. 2018;62:61-73. Crossref

9. Bekaii-Saab TS, Ou FS, Ahn DH, Boland PM, Ciombor KK, Heying EN, et al. Regorafenib dose-optimisation in patients with refractory metastatic colorectal cancer (ReDOS): a randomised, 
multicentre, open-label, phase 2 study. Lancet Oncol. 2019;20:107082. Crossref

10. Tanioka H, Miyamoto Y, Tsuji A, Assayama M, Shiraishi T, Yuki $\mathrm{S}$, et al. Prophylactic effect of dexamethasone on regorafenibrelated fatigue and/or malaise: a randomized, placebo-controlled, double-blind clinical study in patients with unresectable metastatic colorectal cancer (KSCC1402/HGCSG1402). Oncology. 2018;94:289-96. Crossref

11. Petrelli F, Tomasello G, Borgonovo K, Ghidini M, Turati L Dallera $\mathrm{P}$, et al. Prognostic survival associated with left-sided vs right-sided colon cancer: a systematic review and meta-analysis. JAMA Oncol. 2017;3:211-9. Crossref

12. Holch JW, Ricard I, Stintzing S, Modest DP, Heinemann V. The relevance of primary tumour location in patients with metastatic colorectal cancer: A meta-analysis of first-line clinical trials. Eur J Cancer. 2017;70:87-98. Crossref

13. Aggarwal C, Meropol NJ, Punt CJ, Iannotti N, Saidman BH, Sabbath KD, et al. Relationship among circulating tumor cells, CEA and overall survival in patients with metastatic colorectal cancer. Ann Oncol. 2013;24:420-8. Crossret

14. Clinical practice guidelines for the use of tumor markers in breast and colorectal cancer. Adopted on May 17, 1996 by the American Society of Clinical Oncology [editorial]. J Clin Oncol. 1996;14:2843-77. Crossref

15. Lenz HJ, Stintzing S, Loupakis F. TAS-102, a novel antitumor agent: a review of the mechanism of action. Cancer Treat Rev. 2015;41:777-83. Crossref

16. Davies H, Bignell GR, Cox C, Stephens P, Edkins S, Clegg S, et al. Mutations of the $B R A F$ gene in human cancer. Nature. 2002;417:949-54. Crossret

17. Tran B, Kopetz S, Tie J, Gibbs P, Jiang ZQ, Lieu CH, et al. Impact of $B R A F$ mutation and microsatellite instability on the pattern of metastatic spread and prognosis in metastatic colorectal cancer. Cancer. 2011;117:4623-32. Crossref
18. Rowland A, Dias MM, Wiese MD, Kichenadasse G, McKinnon RA, Karapetis CS, et al. Meta-analysis of $B R A F$ mutation as a predictive biomarker of benefit from anti-EGFR monoclonal antibody therapy for $R A S$ wild-type metastatic colorectal cancer. Br J Cancer. 2015;112:1888-94. Crossref

19. Van Cutsem E, Cervantes A, Adam R, Sobrero A, Van Krieken JH, Aderka D, et al. ESMO consensus guidelines for the management of patients with metastatic colorectal cancer. Ann Oncol. 2016;27:1386-422. Crossref

20. Kopetz S, Desai J, Chan E, Hecht JR, O'Dwyer PJ, Maru D, et al. Phase II pilot study of vemurafenib in patients with metastatic $B R A F$-mutated colorectal cancer. J Clin Oncol. 2015;33:40328. Crossref

21. Corcoran RB, Atreya CE, Falchook GS, Kwak EL Ryan DP, Bendell JC, et al. Combined $B R A F$ and $M E K$ inhibition with dabrafenib and trametinib in $B R A F^{\mathrm{V} 600}$-mutant colorectal cancer. J Clin Oncol. 2015;33:4023-31. Crossref

22. Overman MJ, McDermott R, Leach JL, Lonardi S, Lenz HJ, Morse MA, et al. Nivolumab in patients with metastatic DNA mismatch repair-deficient or microsatellite instability-high colorectal cancer (CheckMate 142): an open-label, multicentre, phase 2 study. Lancet Oncol. 2017;18:1182-91. Crossret

23. Le DT, Uram JN, Wang H, Bartlett BR, Kemberling H, Eyring AD, et al.PD-1 blockade in tumors with mismatch-repair deficiency. $\mathrm{N}$ Engl J Med. 2015;372:2509-20. Crossref

24. Overman MJ, Lonardi S, Wong KY, Lenz HJ, Gelsomino F, Aglietta $\mathrm{M}$, et al. Durable clinical benefit with nivolumab plus ipilimumab in DNA mismatch repair-deficient/microsatellite instability-high metastatic colorectal cancer. J Clin Oncol. 2018;36:773-9. Crossref

25. Fukuoka S, Hara H, Takahashi N, Kojima T, Kawazoe A, Asayama M, et al. Regorafenib plus nivolumab in patients with advanced gastric (GC) or colorectal cancer (CRC): An open-label, dose-finding, and dose-expansion phase $1 \mathrm{~b}$ trial (REGONIVO, EPOC1603). J Clin Oncol. 2019;37(15 suppl):2522. Crossref 